\begin{tabular}{|c|l|}
\hline Title & Liquid-phase sensors using open-gate A IGaN /GaN high electron mobility transistor structure \\
\hline Author(s) & Kokawa, Takuya; Sato, Taketomo; Hasegawa, Hideki; Hashizume, Tamotsu \\
\hline Citation & $\begin{array}{l}\text { Journal of Vacuum Science \& Technology B Microelectronics and Nanometer Structures, 24(4), 1972-1976 } \\
\text { https:/doi.org/L0.1116/1.2214701 }\end{array}$ \\
\hline Issue Date & 2006-07-25 \\
\hline Doc URL & http://hdl.handle.net/2115/14592 \\
\hline Type & article \\
\hline File Information & JV STB.pdf \\
\hline
\end{tabular}

Instructions for use 


\title{
Liquid-phase sensors using open-gate AIGaN/GaN high electron mobility transistor structure
}

\author{
Takuya Kokawa, ${ }^{\text {a) }}$ Taketomo Sato, Hideki Hasegawa, and Tamotsu Hashizume \\ Research Center for Integrated Quantum Electronics (RCIQE), Hokkaido University, Kita-Ku, \\ Sapporo 060-8628, Japan and Graduate School of Information Science and Technology, \\ Hokkaido University, Kita-Ku, Sapporo 060-8628, Japan
}

(Received 15 January 2006; accepted 16 March 2006; published 25 July 2006)

\begin{abstract}
Liquid-phase sensing characteristics of open-gate $\mathrm{AlGaN} / \mathrm{GaN}$ high electron mobility transistor (HEMT) structures were investigated in aqueous solutions and polar liquids. In de-ionized water, the open-gate HEMT clearly showed good drain $I-V$ characteristics with current saturation and pinch-off behavior, very similar to $I-V$ characteristics of typical Schottky-gate HEMTs. We observed a fine parallel shift in the transfer curves according to change in the $p \mathrm{H}$ value in a solution, indicating the corresponding potential change at the $\mathrm{AlGaN}$ surface. The sensitivity for the potential change was $57.5 \mathrm{mV} / p \mathrm{H}$, very close to the theoretical value of $58.9 \mathrm{mV} / p \mathrm{H}$ at $24^{\circ} \mathrm{C}$ for the Nernstian response to $\mathrm{H}^{+}$ions. In the low drain bias region, the drain current linearly decreased with the $p \mathrm{H}$ value. This also indicated a systematic potential change at the AlGaN surface due to $p \mathrm{H}$ change. The present open-gate device showed a fast response to the $p \mathrm{H}$ change and a stable operation at fixed $p \mathrm{H}$ values. A possible mechanism for the $p \mathrm{H}$ response of the $\mathrm{AlGaN}$ surface is discussed in terms of equilibrium reactions of hydroxyls at the $\mathrm{AlGaN}$ surface with $\mathrm{H}^{+}$in a solution. It was also found that the device was quite sensitive to changes in the electrostatic boundary conditions of the open-gate area by exposure to polar liquids. The drain current linearly decreased with increasing normalized liquid dipole moment. () 2006 American Vacuum Society.
\end{abstract}

[DOI: $10.1116 / 1.2214701]$

\section{INTRODUCTION}

Chemical sensors using semiconductors which can detect ions, polar molecules, surface adsorption process of molecules, etc., are very attractive not only for various chemicalbut also for biological-sensing applications. Ion-sensitive field effect transistors (ISFETs) using $\mathrm{Si}$ metal-oxidesemiconductor (MOS) structures have extensively been studied. In particular, much effort at investigating $p \mathrm{H}$-sensing membranes and device structures has improved sensitivity and stability of Si ISFET. ${ }^{1-3}$ Utilizing heterostructures and quantum structures, on the other hand, III-V and II-VI compound semiconductors have demonstrated their capabilities in various types of chemical-sensing devices for biochemical processes such as the detection of molecule chemisorption, DNA hybridization, etc. ${ }^{4-7}$ However, such compound semiconductor surfaces are not chemically stable in solutions. Thus, a surface-coating layer is absolutely necessary for chemical sensor structures, causing low sensitivity and slow response of such sensors.

On the basis of excellent optical and electrical properties, significant progress has been achieved in the GaN-based devices, such as ultraviolet laser diodes, white light-emitting diodes, high electron mobility transistors (HEMTs), and high-power FETs. In addition, GaN-based materials are very attractive for various chemical and biological sensor applications because of their superb chemical stability and capability of high-temperature operation owing to their wide gap

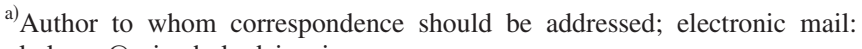
kokawa@rciqe.hokudai.ac.jp nature. The $p \mathrm{H}$ response of $\mathrm{GaN}$ surfaces using ISFET structures was recently reported by Steinhoff $e t$ al. ${ }^{8}$ However, no work on the $p \mathrm{H}$ response to AlGaN surfaces was done, and mechanism of $p \mathrm{H}$ response is not understood yet. Although Stutzmann et al. ${ }^{9}$ and Mehandru et al. ${ }^{10}$ reported preliminary results on the response of open-gate $\mathrm{AlGaN} / \mathrm{GaN}$ HEMTs to polar liquids, the sensing properties of such devices have not systematically been investigated so far.

The purpose of this study is to investigate $p \mathrm{H}$-sensing and liquid-phase sensing characteristics of open-gate $\mathrm{AlGaN} / \mathrm{GaN}$ HEMT structures. We have investigated the basic transistor characteristics and liquid-phase sensing capability of open-gate devices with bare AlGaN surfaces in aqueous solutions. In addition, the ion sensitivity of bare AlGaN surfaces was compared to that of $\mathrm{SiN}_{x}$-passivated surfaces. The results obtained seem to open up the feasibility of cointegration with AlGaN/GaN HEMT circuits for sensor network applications.

\section{EXPERIMENT}

\section{A. Device structure and fabrication process}

As shown in Fig. 1, we used AlGaN/GaN heterostructures with an $\mathrm{Al}$ composition of 0.23 and $\mathrm{AlGaN}$ thickness of $22 \mathrm{~nm}$, grown on sapphire by metal-organic vapor phase epitaxy (MOVPE). The electron mobility and density of the two dimensional electron gas (2DEG) were $950 \mathrm{~cm}^{2} / \mathrm{V}$ and $8.0 \times 10^{12} \mathrm{~cm}^{-2}$, respectively, at room temperature.

The device fabrication process started with isolation patterning using electron-cyclotron resonance (ECR)-assisted 


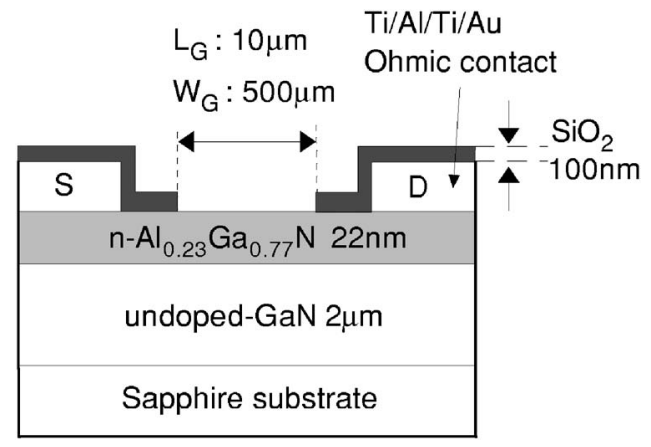

FIG. 1. Structure of the open-gate AlGaN/GaN HEMT.

reactive ion beam etching with a $\mathrm{CH}_{4}$-based gas system consisting of $\mathrm{CH}_{4}, \mathrm{H}_{2}, \mathrm{Ar}$, and $\mathrm{N}_{2}$. The addition of $\mathrm{N}_{2}$ to the gas system is very effective in achieving a smooth and stoichiometric surface. ${ }^{11}$ The drain and source electrodes were formed by deposition of $\mathrm{Ti} / \mathrm{Al} / \mathrm{Ti} / \mathrm{Au}$ multilayers and annealing at $800{ }^{\circ} \mathrm{C}$ for $1 \mathrm{~min}$. Then, the device surface was covered with $\mathrm{SiO}_{2}$ film to a thickness of $100 \mathrm{~nm}$ using plasma-enhanced chemical vapor deposition (PECVD) at $300{ }^{\circ} \mathrm{C}$. The open-gate area, length of $10 \mu \mathrm{m}$ and width of $500 \mu \mathrm{m}$, was formed through photolithography and wet etching processes in a buffered HF solution. The final structure is as shown in Fig. 1.

\section{B. Electrochemical cell and measurement circuit}

Figure 2 shows an electrochemical cell and a measurement circuit consisting of a potentiostat (EG\&G, 273AEC) and a semiconductor parameter analyzer (Agilent, 4156C). The open-gate devices were set on a Teflon holder, and the source and drain electrodes were covered by a negative-type photoresist. The gate bias was applied from the semiconductor parameter analyzer to the electrolyte/AlGaN interface at the open-gate area via a saturated calomel electrode (SCE). For $p \mathrm{H}$-sensing measurements, we prepared de-ionized (DI) water and a mixed solution with $\mathrm{HCl}$ and $\mathrm{NaOH}$ in DI water.

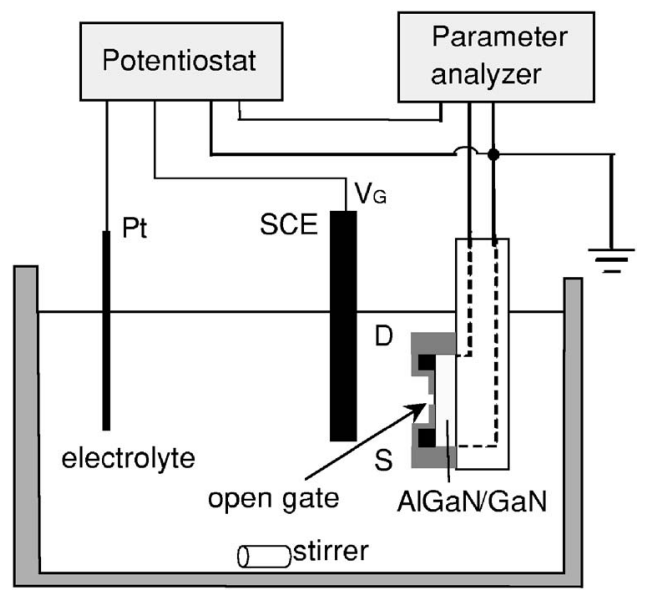

FIG. 2. Schematic of the electrochemical cell and the measurement circuit. The open-gate devices were set on a Teflon holder. The source and drain electrodes were covered by a negative-type photoresist.

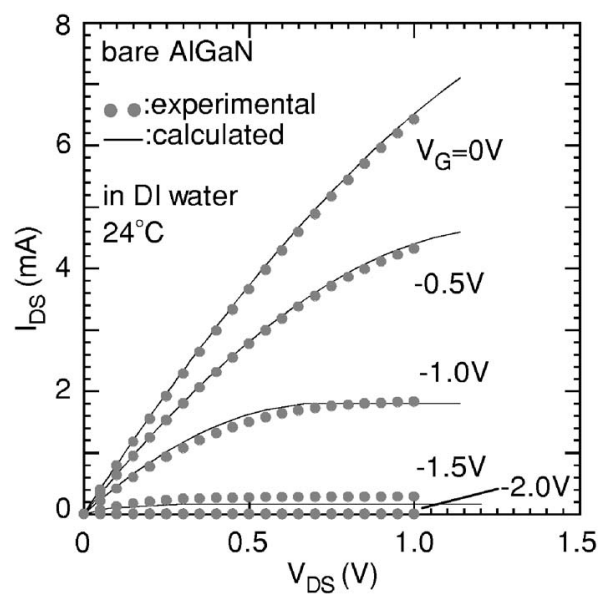

FIG. 3. Typical drain $I-V$ characteristics of the open-gate HEMT in DI water at $24{ }^{\circ} \mathrm{C}$ under dark conditions. The gate bias was applied to the open-gate area via a SCE.

The $p \mathrm{H}$ values in solutions were measured using a digital $p \mathrm{H}$ meter (CyberScan, pH100). For polar liquids, we used ethanol and acetone. All measurements in solutions were performed at $24{ }^{\circ} \mathrm{C}$ under dark conditions.

\section{RESULTS AND DISCUSSION}

\section{A. $I-V$ characteristics of the open-gate HEMT in de- ionized water}

Figure 3 shows typical drain $I-V$ characteristics of the open-gate HEMT in DI water at $24^{\circ} \mathrm{C}$ under dark conditions. The device clearly exhibits current saturation and pinch-off behavior, which is very similar to $I-V$ characteristics of typical Schottky-gate HEMTs. This shows that the potential of the AlGaN surface in the open gate can effectively be controlled by the solution potential. The solid lines in Fig. 3 indicate the calculated curves based on the gradualchannel approximation together with a field-dependent mobility formula. The source and contact resistances were considered in the calculation. The experimental $I-V$ curves were reproduced very well by the calculation. From the calculated results, we estimated the value of $1.5 \mathrm{eV}$ for the flat-band potential at the water/AlGaN interface, which is very close to the charge neutrality level (CNL) of $1.6 \mathrm{eV}$ for $\mathrm{Al}_{0.23} \mathrm{Ga}_{0.77} \mathrm{~N} .{ }^{12}$ Fujii and Ohkawa recently reported ${ }^{13}$ that the flat-band potential of $n$-GaN was about $1.0 \mathrm{eV}$ in $\mathrm{Na}_{2} \mathrm{SO}_{4}$ solution $(p \mathrm{H}=6.7)$. This value is also very close to $\mathrm{CNL}$ of $1.03 \mathrm{eV}$ for GaN. ${ }^{12}$

The gate-leakage characteristics of the open-gate HEMT in de-ionized water is shown in Fig. 4, together with a typical $I_{G S^{-}} V_{G S}$ curve of the Ni/Au Schottky-gate HEMT in air. The Schottky-gate device showed large leakage currents with a pronounced bias dependence, which can be explained by enhancement of electron tunneling transport through the metal$\mathrm{AlGaN}$ interface caused by the unintentionally induced surface donors. ${ }^{14,15}$ In comparison, the open-gate HEMT brought low gate currents in solution, probably due to few carriers (electrons and holes) in the electrochemical system 


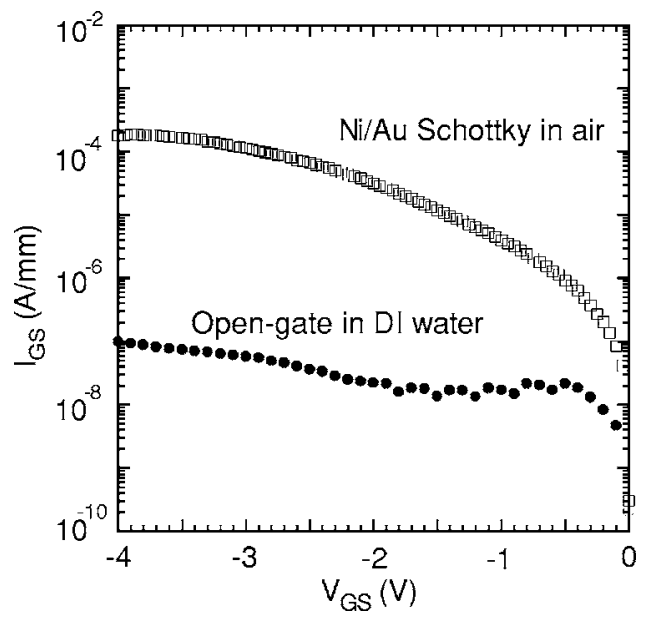

FIG. 4. Gate $I$ - $V$ characteristics of the open-gate HEMT in DI water at $24{ }^{\circ} \mathrm{C}$ under dark conditions. For comparison, typical $I_{G S}-V_{G S}$ curve of a Schottkygate HEMT is plotted.

under dark conditions. Similar gate $I-V$ characteristics were observed in other solutions. This indicated that the effects of gate leakage on the potential control of solution/AlGaN interfaces can be ignored, resulting in good gate control of drain current via the SCE, as shown in Fig. 3.

\section{B. $\mathrm{pH}$ response of the open-gate HEMT}

Figure 5 shows the transfer characteristics of the opengate HEMT in a mixed solution of $\mathrm{HCl}$ and $\mathrm{NaOH}$ in water with different $p \mathrm{H}$ values. To evaluate the transfer characteristics in the linear region, we set the drain bias at $0.2 \mathrm{~V}$. A fine parallel shift was observed in the transfer curves, when the $p \mathrm{H}$ value changed from 4.0 to 10.0 , indicating the corresponding potential change at the AlGaN surface. The sensitivity for the potential change is $57.5 \mathrm{mV} / p \mathrm{H}$, very close to the theoretical value of $58.9 \mathrm{mV} / \mathrm{pH}$ at $24{ }^{\circ} \mathrm{C}$ for the Nernstian response to $\mathrm{H}^{+}$ions.

Figure 6 shows the drain current measured under $V_{G S}$ $=-0.5 \mathrm{~V}$ and $V_{D S}=0.2 \mathrm{~V}$ as a function of the $p \mathrm{H}$ value. As

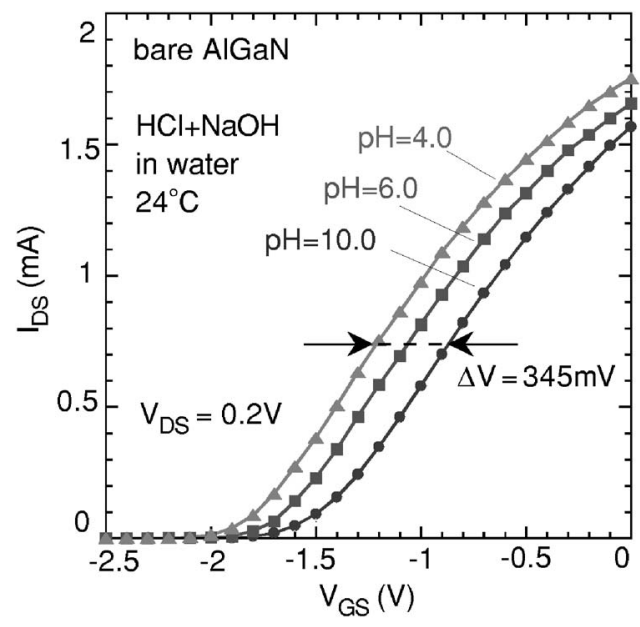

FIG. 5. Transfer characteristics of the open-gate HEMT in a mixed solution of $\mathrm{HCl}$ and $\mathrm{NaOH}$ in water with different $p \mathrm{H}$ values.

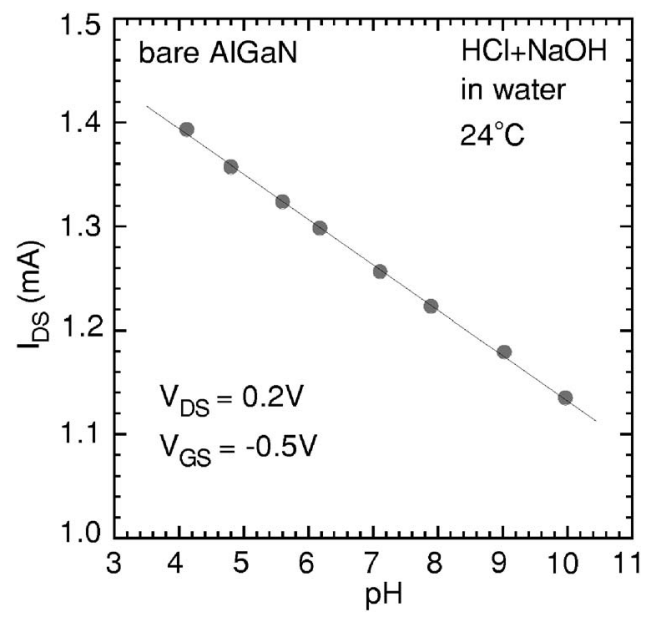

FIG. 6. Drain current measured under $V_{G S}=-0.5 \mathrm{~V}$ and $V_{D S}=0.2 \mathrm{~V}$ as a function of the $p \mathrm{H}$ value.

expected from the result in Fig. 5, the drain current decreased with the $p \mathrm{H}$ value. We obtained a large current change, over $200 \mu \mathrm{A}$, when the $p \mathrm{H}$ value was changed from 4.3 to 10.0 , because of high mobility and 2DEG density of the $\mathrm{AlGaN} / \mathrm{GaN}$ HEMT. In addition, a linear behavior was clearly observed, reflecting systematic change in potential at the $\mathrm{AlGaN}$ surface in the linear bias region.

The exact mechanism of how these changes occur is still unknown. For electrolyte-insulator interfaces $\left(\mathrm{SiO}_{2}, \mathrm{SiN}_{x}\right.$, $\mathrm{Al}_{2} \mathrm{O}_{3}$, AlN, etc.) in Si-based ion-sensitive FETs, a sitebinding model is generally accepted. ${ }^{1,2,16}$ According to this model, hydroxyl groups ( $M \mathrm{OH}: M$ represents $\mathrm{Si}$ or metals) are formed at insulator surfaces in contact with aqueous solutions, and can dissociate to or combine with $\mathrm{H}^{+}$, depending on the $\mathrm{H}^{+}$concentration and the equilibrium constants for the relevant reactions, as follows:

$$
\begin{aligned}
& M \mathrm{OH} \rightleftarrows M \mathrm{O}^{-}+\mathrm{H}^{+}, \\
& M \mathrm{OH}+\mathrm{H}^{+} \rightleftarrows M \mathrm{OH}_{2}{ }^{+} .
\end{aligned}
$$

When the $\mathrm{H}^{+}$concentration decreases in solution, the rightdirection reaction in the equilibrium equation (1) becomes dominant, resulting in negative charges at the insulator surfaces due to deprotonized hydroxyls $\left(\mathrm{MO}^{-}\right)$. On the other hand, the increase of $\mathrm{H}^{+}$can induce positive charges at the surfaces due to protonized hydroxyls $\left(\mathrm{MOH}_{2}^{+}\right)$, represented by Eq. (2). This leads to a $p \mathrm{H}$-dependent net charge at the insulator surfaces, and the liquid-solid interfacial potential thereby follows the Nernst equation.

The simplest model for the present open-gate HEMT is an analogy of this mechanism. To investigate the control mechanism of the interfacial potential, we fabricated and characterized another device with a $\mathrm{SiN}_{x}$-covered $\mathrm{AlGaN}$ surface, as shown in Fig. 7(a). A thin $\mathrm{SiN}_{x}$ film with a thickness of $10 \mathrm{~nm}$ was deposited on the surface by ECR-assisted CVD at $270{ }^{\circ} \mathrm{C}$. It is known that $\mathrm{SiN}_{x} / \mathrm{AlGaN}$ structures show good interface properties with low interface state densities, ${ }^{17}$ and that a $\mathrm{SiN}_{x}$-based surface passivation improves operation stability of AlGaN/GaN HEMTs. ${ }^{18,19}$ 


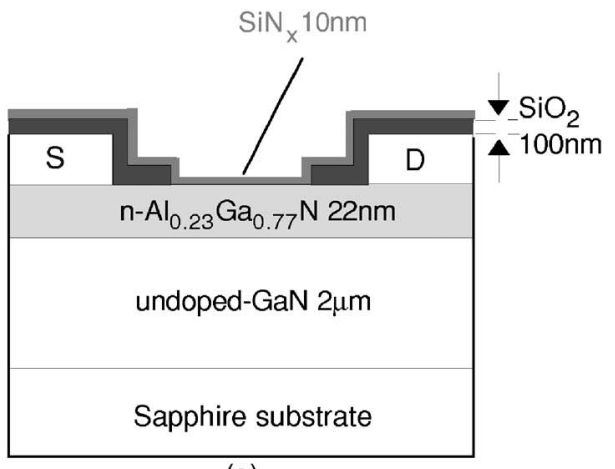

(a)

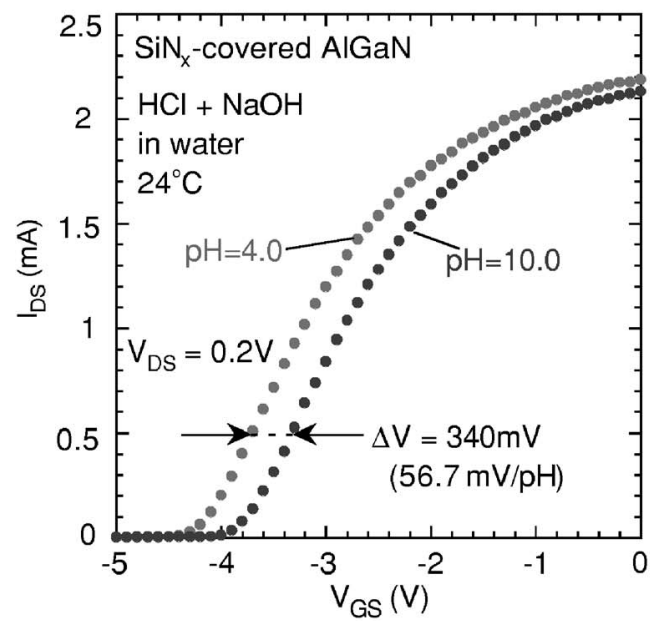

(b)

FIG. 7. (a) Structure of the open-gate HEMT with a $\mathrm{SiN}_{x}$-covered AlGaN surface. (b) The transfer characteristics of the open-gate HEMT with $\mathrm{SiN}_{x}$-covered $\mathrm{AlGaN}$ in a mixed solution of $\mathrm{HCl}$ and $\mathrm{NaOH}$ in water with different $p \mathrm{H}$ values.

Figure 7(b) shows the transfer characteristics of the opengate HEMT with $\mathrm{SiN}_{x}$-covered AlGaN in a mixed solution of $\mathrm{HCl}$ and $\mathrm{NaOH}$ in water with different $p \mathrm{H}$ values. It is noted that the insertion of the $\mathrm{SiN}_{x}$ layer on the AlGaN surface caused the shift in intrinsic threshold voltage toward deeper gate bias. We observed a parallel shift in the transfer characteristics with change in $p \mathrm{H}$, similar to the device without the $\mathrm{SiN}_{x}$ layer. The $p \mathrm{H}$ sensitivity obtained was $56.7 \mathrm{mV} / p \mathrm{H}$, very close to that of the device without the $\mathrm{SiN}_{x}$ layer. Almost the same value of $55.8 \mathrm{mV} / \mathrm{pH}$ was reported for the AlN-gate Si ISFET. ${ }^{3}$ Thus, it is likely that the mechanism explained above controls the potential of the solution-AlGaN interface for the present $\mathrm{AlGaN} / \mathrm{GaN}$ open-gate HEMT. Steinhoff et al. pointed out ${ }^{8}$ that natural oxide such as $\mathrm{GaO}_{x}$ on the $\mathrm{GaN}$ surface could be responsible for the $p \mathrm{H}$ response of GaN-based $p \mathrm{H}$-sensitive FETs. However, it is known that Ga oxides are soluble in alkaline solutions. ${ }^{20,21}$ Thus it seems impossible that such a natural oxide acts as a stable insulator layer at $\mathrm{GaN}$ surfaces in a solution with a wide $p \mathrm{H}$ range. There still remains the possibility that the potential at the solution-AlGaN interface is governed by direct adsorption of

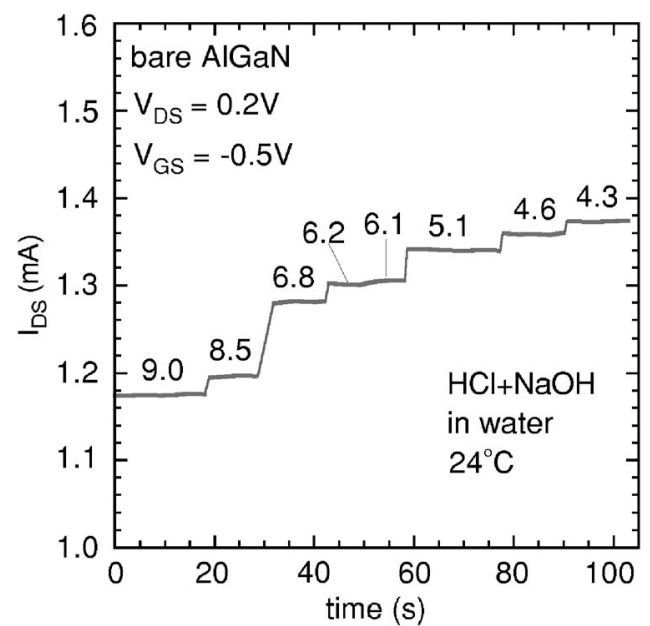

FIG. 8. Transient behavior of $I_{D S}$ as a function of the $p H$ value. The numbers indicate corresponding $p \mathrm{H}$ values in a mixed solution of $\mathrm{HCl}$ and $\mathrm{NaOH}$ in water.

ions at the given sites of the AlGaN surface. Further investigation is necessary to confirm the exact mechanism of $p \mathrm{H}$ response of the $\mathrm{AlGaN}$ surface.

To investigate the operational stability of the $\mathrm{AlGaN} / \mathrm{GaN}$ ISFET, we performed time-resolved measurements of $I_{D S}$ under $V_{G S}=-0.5 \mathrm{~V}$ and $V_{D S}=0.2 \mathrm{~V}$. The device showed a fairly good stability and immediate response to change in $p \mathrm{H}$, as shown in Fig. 8. The response time was estimated to be 100-200 ms which seems to be limited not by the intrinsic device response but by the $\mathrm{pH}$ exchange rate in the solution.

\section{Drain current response to polar liquids}

Finally, we investigated the sensitivity of the present device to polar liquids. The drain current in the linear bias region was measured in DI water $(p \mathrm{H}$ of 6.8$)$, methanol $(p \mathrm{H}$ of 6.9), and acetone ( $p \mathrm{H}$ of 6.9). It was found that the device was also quite sensitive to changes in the electrostatic boundary conditions of the open-gate area by exposure to polar liquids.

Figure 9 shows $I_{D S}$ as a function of the $p / \varepsilon$ value for each liquid, where $p$ and $\varepsilon$ are the dipole moment and the relative permittivity, respectively, of the liquid. In the simplest approximation, the potential drop $\Delta V$ at the liquid-solid interface due to the molecule's dipole moment can be described by the well-known Helmholtz model: ${ }^{4}$

$$
\Delta V=\frac{N_{s} p(\cos \theta)}{\varepsilon \varepsilon_{0}},
$$

where $p$ is the dipole moment, $N_{s}$ is the dipole density per unit area, $\theta$ is the angle between the dipole and the surface normal, $\varepsilon$ is the relative permittivity of the liquid, and $\varepsilon_{0}$ is the permittivity of free space. The present device showed a good linear behavior shown in Fig. 9, indicating the potential change at the AlGaN surface due to change in dipole moment in each liquid. The response time was estimated to be several hundred milliseconds. Bastide et al. reported ${ }^{4}$ a simi- 


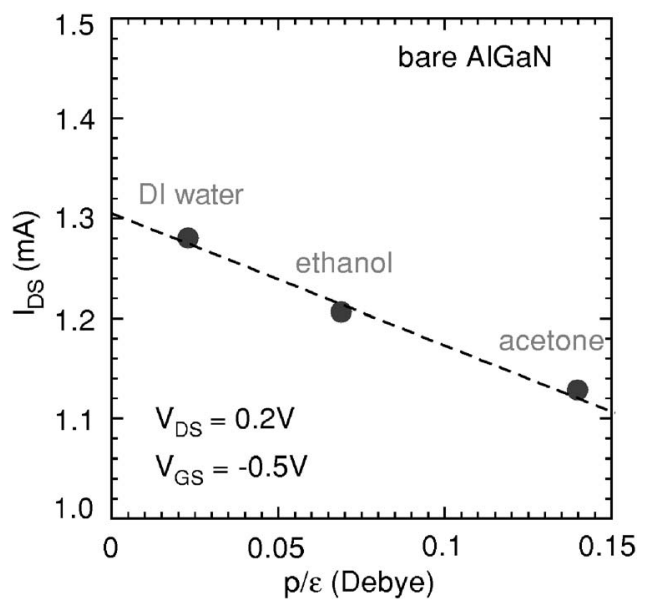

FIG. 9. Drain currents in DI water, ethanol, and acetone, as a function of the $p / \varepsilon$ value for each liquid, where $p$ and $\varepsilon$ are the dipole moment and the relative permittivity of the liquid.

lar behavior in the surface potential of GaAs by adsorption of benzoic acid. Luber et al. ${ }^{7}$ reported that an AlGaAs/GaAs device coated by a self-assembled biphenyl layer showed a similar response to polar liquids. However, the response time is very long, e.g., several tens of minutes, probably due to the coating layer. On the other hand, no surface passivation is necessary for the present device, thereby resulting in an immediate response to polar liquids. Thus, the results obtained indicate that the present open-gate $\mathrm{AlGaN} / \mathrm{GaN}$ HEMT can effectively distinguish molecules with different dipole moments.

\section{SUMMARY}

We have investigated the $p \mathrm{H}$-sensing and liquid-phase sensing characteristics of open-gate $\mathrm{AlGaN} / \mathrm{GaN}$ HEMT structures in aqueous solutions and polar liquids. In DI water, the open-gate HEMT clearly showed good drain $I-V$ characteristics with current saturation and pinch-off behavior, which is very similar to $I-V$ characteristics of typical Schottky-gate HEMTs. We observed a fine parallel shift in the transfer curves according to change in the $p \mathrm{H}$ value in a solution, indicating the corresponding potential change at the AlGaN surface. The sensitivity of the potential change is $57.5 \mathrm{mV} / p \mathrm{H}$, very close to the theoretical value of $58.9 \mathrm{mV} / p \mathrm{H}$ at $24{ }^{\circ} \mathrm{C}$ for the Nernstian response to $\mathrm{H}^{+}$ions. In the low drain bias region, the drain current linearly decreased with the $p \mathrm{H}$ value. This also indicated a systematic potential change at the AlGaN surface due to the $p \mathrm{H}$ change.
The present open-gate device showed a fast response to the $p \mathrm{H}$ change and a stable operation under the fixed $p \mathrm{H}$ value. A possible mechanism for the $p \mathrm{H}$ response of the AlGaN surface was discussed in terms of equilibrium reactions of hydroxyls at the $\mathrm{AlGaN}$ surface with $\mathrm{H}^{+}$in a solution. It was also found that the device was quite sensitive to changes in the electrostatic boundary conditions of the open-gate area by exposure to polar liquids. The drain current linearly decreased with increasing normalized liquid dipole moment. These results indicate that the open-gate $\mathrm{AlGaN} / \mathrm{GaN}$ HEMTs are very promising as high-sensitivity liquid-phase sensors for chemical and biological sensor-chip applications.

\section{ACKNOWLEDGMENT}

This work was partly supported by the 21st Century COE Project on "Meme-Media-Based Next-Generation ITs" from MEXT, Japan.

${ }^{1}$ M. Esashi and T. Matsuo, IEEE Trans. Biomed. Eng. 25, 184 (1978).

${ }^{2}$ L. Bousse, N. F. De Rooij, and P. Bergveld, IEEE Trans. Electron Devices ED-30, 1263 (1983)

${ }^{3}$ L. Chiang, Y.-C. Chen, and J.-C. Chou, Jpn. J. Appl. Phys., Part 1 40, 5900 (2001).

${ }^{4}$ S. Bastide, R. Butruille, D. Cahen, A. Dutta, J. Libman, A. Shanzer, L. Sun, and A. Vilan, J. Phys. Chem. B 101, 2678 (1997).

${ }^{5}$ E. F. Duus et al., Phys. Status Solidi B 224, 871 (2001).

${ }^{6}$ A. Shaporenko, K. Adlkofer, L. S. O. Johansson, M. Tanaka, and M. Zharnikov, Langmuir 19, 4992 (2003).

${ }^{7}$ S. M. Luber et al., Physica E (Amsterdam) 21, 1111 (2004).

${ }^{8}$ G. Steinhoff, M. Hermann, W. J. Schaff, L. F. Eastman, M. Stutzmann, and M. Eickhoff, Appl. Phys. Lett. 83, 177 (2003).

${ }^{9}$ M. Stutzmann, G. Steinhoff, M. Eickhoff, O. Ambacher, C. E. Nebel, J. Schalwig, R. Neuberger, and G. Muller, Diamond Relat. Mater. 11, 886 (2002).

${ }^{10}$ R. Mehandru et al., Solid-State Electron. 48, 351 (2004).

${ }^{11}$ Z. Jin, T. Hashizume, and H. Hasegawa, Appl. Surf. Sci. 190, 361 (2002).

${ }^{12}$ W. Mönch, Appl. Surf. Sci. 117/118, 380 (1997).

${ }^{13}$ K. Fujii and K. Ohkawa, Jpn. J. Appl. Phys., Part 2 44, L909 (2005).

${ }^{14}$ T. Hashizume, J. Kotani, and H. Hasegawa, Appl. Phys. Lett. 84, 4884 (2004).

${ }^{15}$ J. Kotani, S. Kasai, T. Hashizume, and H. Hasegawa, J. Vac. Sci. Technol. B 23, 1799 (2005).

${ }^{16}$ D. E. Yates, S. Levine, and T. W. Healy, J. Chem. Soc., Faraday Trans. 1 70, 1807 (1974)

${ }^{17}$ T. Hashizume, S. Ootomo, T. Inagaki, and H. Hasegawa, J. Vac. Sci. Technol. B 21, 1828 (2003).

${ }^{18}$ B. M. Green, K. K. Chu, E. M. Chumbes, J. A. Smart, J. M. Shealy, and L. F. Eastman, IEEE Electron Device Lett. 21, 268 (2000).

${ }^{19}$ T. Mizutani, Y. Ohno, M. Akita, S. Kishimoto, and K. Maezawa, Phys. Status Solidi A 194, 447 (2002).

${ }^{20}$ K. Prabhakaran, T. G. Andersson, and K. Nozawa, Appl. Phys. Lett. 69, 3212 (1996).

${ }^{21}$ T. Hashizume, S. Ootomo, R. Nakasaki, S. Oyama, and M. Kihara, Appl. Phys. Lett. 76, 2880 (2000). 